\title{
ANALISIS PENDAPATAN USAHATANI PADI DAN PERSEPSI PETANI DALAM PROGRAM GERAKAN PENERAPAN PENGELOLAAN TANAMAN TERPADU (GP-PTT) PADI DI KECAMATAN BEBANDEM KABUPATEN KARANGASEM
}

\section{Income Analysis and Farmer's Perception on the Application of Paddy Integrated Management Program at Bebandem District Karangasem Regency}

\author{
I Putu Eka Budi Antara, IGAA Ambarawati, Ketut Suamba
}

Program Studi Magister Agribisnis, Fakultas Pertanian, Universitas Udayana, Bali, Indonesia

E-mail : biputueka@gmail.com

\begin{abstract}
Regency of Karangasem is one of regencies in Bali Province carried out a program of paddy integrated management, known as GP-PTT. This program is aimed to increase rice production nationally for food security. This research is intended to analyze farm income and to find out farmer's perception on the paddy integrated management program as well as obstacles in the application of the program. This research was carried out at Bebandem District, Regency of Karangasem, selected purposively, as this area obtained the highest proportion of the program area to conduct compared to other regions. Primary data collection was carried out through survey and interview, while secondary data were obtained through desk research and publication searching. A t-test with two independent samples was conducted to find out farm income difference between farmers under the GP-PTT program and without the program. Farmer's perception on the program was analyzed descriptive qualitatively through the use of score. Results of the research shows that the average of farmer's income under the GP-PTT program was Rp 14,180,962.04 per hectare per planting season with the R/C ratio was 2.8. On the other hand, farmer's income for non program was $R p$ 14,095,526.91 with the $R / C$ of 3.23. Result of the $t$-test shows that there is no significant difference between the two incomes. Farmer's perception on the program was categorized as in doubt with the score of 3.24. Technical impediment faced by farmers was short of planting machine to follow suggested legowo system in place. Economic impediment felt by the farmers is that this program leads to increase the cost of manpower. It is also found in planting system in that farmers are facing difficulties in applying suggested technology of legowo system while farmers are accustomed to tegel system. In order to follow up the GP-PTT program, it is suggested to the government to support farmers continuously until they are willing to and are able to apply the suggested technology.
\end{abstract}

Kata kunci: GP-PTT, farmer income, R/C Ratio, farmer's perception

\begin{abstract}
ABSTRAK
Kabupaten Karangasem merupakan salah satu kabupaten di Provinsi Bali yang melaksanakan program pengelolaan terpadu padi, yang dikenal dengan nama GP-PTT. Program ini bertujuan untuk meningkatkan produksi padi secara nasional untuk ketahanan pangan. Penelitian ini bertujuan untuk menganalisis pendapatan usahatani dan untuk mengetahui persepsi petani terhadap program pengelolaan terpadu padi serta hambatan dalam penerapan program. Penelitian ini dilakukan di Kabupaten Bebandem, Kabupaten Karangasem, dipilih secara purposif, karena daerah ini memperoleh proporsi tertinggi dari wilayah program untuk melakukan operasi dibandingkan dengan daerah lain. Pengumpulan data primer dilakukan melalui survei dan wawancara, sedangkan data sekunder diperoleh melalui penelitian deskriptif dan pencarian publikasi. Uji t dengan dua sampel independen dilakukan untuk mengetahui perbedaan pendapatan petani antara petani dengan program GP-PTT dan tanpa program. Persepsi petani terhadap program dianalisis secara deskriptif secara kualitatif melalui penggunaan skor. Hasil penelitian menunjukkan bahwa rata-rata pendapatan petani di bawah program GP-PTT adalah Rp 14.180.962,04 per hektar per musim tanam dengan rasio R / C 2,8. Di sisi lain, pendapatan petani untuk non program adalah Rp 14.095.526,91 dengan R / C 3,23. Hasil uji-t menunjukkan bahwa tidak ada perbedaan yang signifikan antara kedua pendapatan tersebut. Persepsi petani terhadap program ini tergolong meragukan dengan skor 3,24. Hambatan teknis yang dihadapi petani adalah minimnya mesin tanam untuk mengikuti sistem legowo yang disarankan. Hambatan ekonomi yang dirasakan oleh petani adalah program ini menyebabkan kenaikan biaya tenaga kerja. Hal ini juga ditemukan pada sistem tanam dimana petani menghadapi kesulitan dalam menerapkan teknologi dugaan sistem legowo sementara petani terbiasa dengan sistem tegel. Untuk menindaklanjuti program
\end{abstract}


GP-PTT, disarankan kepada pemerintah untuk mendukung petani secara terus menerus sampai mereka bersedia dan mampu menerapkan teknologi yang disarankan.

Kata kunci: GP-PTT, pendapatan petani, rasio R / C, persepsi petani

\section{PENDAHULUAN}

Peningkatan produksi padi di Indonesia pada tahun 2015 difokuskan pada kawasan tanaman pangan, melalui Gerakan Penerapan Pengelolaan Tanaman Terpadu (GP-PTT) dengan fasilitas bantuan sarana produksi (saprodi), tanam jajar legowo dan pertemuan kelompok pada seluruh area program GP-PTT sebagai instrumen stimulan disertai dengan dukungan pembinaan oleh berbagai pihak. Sejalan dengan fasilitas bantuan yang diberikan pemerintah pada seluruh areal program, maka luas GP-PTT padi tahun 2015 adalah sebesar 350.000 ha.

Provinsi Bali mendapatkann program GP-PTT padi sawah pada tahun 2015 sebanyak enam unit dengan luas 7.500 ha. Kabupaten Karagasem, merupakan salah satu kabupaten di Provinsi Bali yang mendapatkan program GP-PTT padi. Luas lahan program GP-PTT padi di Kabupaten Karangasem pada tahun 2015 adalah 1.000 ha, dengan jumlah dana sebesar $\mathrm{Rp} 2,9$ milyar diterima oleh 27 subak yang tersebar di empat kecamatan.

Program GP-PTT padi di Kabupaten Karangasem sudah selesai dilaksanakan, tetapi belum diketahui hasil analisis pendapatan usahatani padi dan persepsi petani dalam program tersebut. Untuk itu perlu dilakukan analisis pendapatan usahatani padi dalam program GP-PTT padi.

\section{RUMUSAN MASALAH}

Rumusan masalah penelitian ini adalah sebagai berikut:

1. Bagaimanakah pendapatan petani dari usahatani padi sawah dalam program GP-PTT padi di Kabupaten Karangasem?

2. Bagaimana persepsi petani di Kabupaten Karangasem terhadap program GP-PTT padi?

3. Kendala-kendala apa yang dijumpai dalam pelaksanaan program GP-PTT padi di tingkat lapang?

\section{TUJUAN PENELITIAN}

Tujuan dari penelitian ini adalah sebagai berikut.

1. Untuk mengetahui pendapatan usahatani padi sawah dalam program GP-PTT padi di Kabupaten Karanagsem.

2. Untuk mengetahui persepsi petani di Kabupaten Karangasem terhadap program GP-PTT padi.

3. Untuk mengetahui kendala-kendala yang dijumpai dalam pelaksanaan program GP-PTT padi di tingkat lapang.

\section{KAJIAN PUSTAKA}

\section{Usahatani}

Menurut Rahim dan Diah (2008), usahatani adalah ilmu yang mempelajari tentang cara petani mengelola input atau faktor-faktor produksi (tanah, tenaga kerja, modal, teknologi, pupuk, benih, dan pestisida) dengan efektif, efisien, dan kontinyu untuk menghasilkan produksi yang tinggi sehingga pendapatan usahatani meningkat.

\section{Biaya usahatani}

Menurut Hermanto (1988), biaya usahatani adalah nilai korbanan yang dikeluarkan untuk memperoleh hasil. Menurut kerangka waktu, biaya dapat dibedakan menjadi biaya jangka pendek dan biaya jangka panjang. Biaya jangka pendek terdiri dari biaya tetap (fixed cost) dan biaya variabel (variable cost), sedangkan dalam jangka panjang semua biaya dianggap/diperhitungkan sebagai biaya variabel.

\section{Penerimaan usahatani}

Menurut Sumarni (2011), penerimaan usahatani merupakan total penerimaan dari kegiatan usahatani yang diterima pada akhir proses produksi. Penerimaan usahatani dapat pula diartikan sebagai keuntungan material yang diperoleh seorang petani atau bentuk imbalan jasa petani maupun keluarganya sebagai pengelola usahatani maupun akibat pemakaian barang modal yang dimilikinya.

Menurut Soekartawi (1995), penerimaan usahatani adalah perkalian anatara produksi yang diperoleh dengan harga jual yang dinyatakan dengan rumus:

$$
\begin{aligned}
& \mathrm{TR}_{\mathrm{i}}=\mathrm{Y}_{\mathrm{i}} \cdot \mathrm{Py}_{\mathrm{i}} \\
& \text { dimana: } \quad \mathrm{TR}=\text { total penerimaan } \\
& \mathrm{Y}=\text { produksi yang diperoleh } \\
& \text { dalam suatu usahatani } i \\
& \text { Py = harga } \mathrm{Y}
\end{aligned}
$$

\section{Pendapatan usahatani}

Menurut Hadisapoetra (1979), pendapatan usahatani adalah total pendapatan bersih yang diperoleh dari seluruh aktifitas usahatani yang merupakan selisih antara total penerimaan dengan total biaya yang dikeluarkan. Sedangkan menurut Soekartawi (1995), pendapatan usahatani adalah selisish antara penerimaan dan semua biaya yang dinyatakan dengan rumus :

$$
\begin{array}{ll} 
& \mathrm{Pd}=\mathrm{TR}-\mathrm{TC} \\
\text { dimana: } & \mathrm{Pd}=\text { pendapatan usahatani }
\end{array}
$$

Eka Budi, et. al., Analisis Pendapatan....|14 


$$
\begin{aligned}
& \mathrm{TR}=\text { total penerimaan } \\
& \mathrm{TC}=\text { total biaya }
\end{aligned}
$$

\section{Analisis R/C Ratio}

Menurut Gunaantari (2010), analisis $R / C$ Ratio digunakan untuk mengetahui apakah suatu usahatani masih layak atau tidak untuk diusahakan, mengingat keadaan usahatani tersebut disuatu wilayah tertentu perlu mendapatkan pertimbangan untuk diusahakan. Selain itu $R / C$ Ratio juga bisa digunakan untuk melihat tingkat efisiensi dari suatu usahatani padi sawah. Efisiensi adalah ukuran kemampuan suatu sistem usahatani menghasilkan keuntungan (atau paling tidak mencapai titik impas) ketika tidak ada kebijakan pemerintah atau ketidaksempurnaan pasar yang mempengaruhi produksi.

\section{Persepsi Petani tentang GP-PTT Padi}

Menurut Ardiyani (2009), secara umum persepsi adalah tanggapan yang terorganisasi melalui proses memahami, menafsirkan, menginterpretasikan dan memikirkan secara sadar terhadap suatu rangsangan objek. Dalam hubungannya dengan persepsi tentang bantuan GP-PTT padi, tentu sebelumnya didahului oleh proses mengetahui, memahami sampai muncul penafsiran yang bermacam-macam dari petani tentang bantuan GP-PTT padi atau tidak muncul penafsiran sama sekali karena di memori petani sama sekali kosong dari pengetahuan dan pemahaman tentang GP-PTT padi.

\section{METODE PENELITIAN}

\section{Penentuan Lokasi dan Waktu Penelitian}

Lokasi penelitian adalah di Kabupaten Karangasem, Provinsi Bali yang ditentukan dengan metode purposive sampling. Penelitian ini merupakan studi kasus di Kecamatan Bebandem, Kabupaten Karangasem. Adapun beberapa pertimbangan pemilihan lokasi penelitian yaitu sebagai berikut:

1. Kabupaten Karangasem adalah salah satu kabupaten di Provinsi Bali yang mendapatkan program GP-PTT padi seluas 1.000 ha.

2. Kecamatan Bebandem merupakan kecamatan yang mendapat program GP-PTT padi terluas di Kabupaten Karangasem dengan luas 350 ha.

Waktu penelitian dilaksanakan dari bulan Agustus tahun 2015 sampai denganJanuari tahun 2017.

\section{Populasi dan Sampel}

Jumlah populasi sebanyak 1.153 orang petani yang merupakan anggota dari 11 Subak yang tersebar di lima desa di Kecamatan Bebandem. Penentuan jumlah sampel dari populasi dilakukan dengan teori Slovin. Dalam mendapatkan data selain 92 orang sampel juga didapat dari 92 orang responden yaitu petani padi sawah di Kecamatan Bebandem yang tidak mendapat program GP-PTT padi tahun 2015. Penentuan jumlah sampel tiap kelompok dilakukan dengan proporsional secara accidental sampling berdasarkan jumlah populasi di masing-masing Kelompok/Subak.

\section{Sumber data}

Sumber data yang digunakan adalah data primer dan data sekunder. Data primer merupakan data yang dikumpulkan langsung dari lapangan dengan metode wawancara dengan menggunakan kuesioner yang telah disiapkan sebelumnya. Data primer diperoleh langsung dari sumber pertama (responden) yang telah ditentukan. Data sekunder adalah data yang dikumpulkan dari sumber tidak langsung (sumber kedua) umumnya diperoleh dari badan/dinas/instansi yang bergerak dalam proses pengumpulan data baik instansi pemerintah maupun swasta. Data sekunder dalam penelitian ini bersumber dari Dinas Pertanian Tanaman Pangan dan Hortikultura Kabupaten Karangasem, Badan Pusat Statistik Kabupaten Karangasem, serta sumber-sumber lain baik hasil penelitian terdahulu maupun kajian teoritis.

\section{Jenis Data}

Jenis data yang dibutuhkan dalam penelitian ini adalah data kualitatif dan data kuantitatif. Data kualitatif adalah data yang terbentuk kata, kalimat, skema dan gambar, atau data yang tidak berupa angka dan tidak dapat dihitung, tetapi berupa penjelasan yang berhubungan dengan objek penelitian. Data kuantitatif adalah data yang diukur dengan suatu alat ukur tertentu yang diperlukan untuk keperluan analisis secara kuantitatif yang berbentuk angka - angka.

\section{Metode Pengumpulan Data}

Metode yang digunakan dalam pengumpulan data dalam penelitian ini adalah sebagai berikut.

1. Wawancara (interview), yaitu pengumpulan data dengan cara meminta keterangan dari responden dengan berpedoman pada daftar pertanyaan yang telah disiapkan sebelumnya.

2. Observasi yaitu suatu pengumpulan data dengan pengamatan langsung di lapangan untuk menguji dan melengkapi data lainya, dengan menggunakan instrumen panduan pengamatan.

3. Dokumentasi yaitu pengumpulan data melalui arsip-arsip atau naskah-naskah yang berhubungan dengan penelitian sebagai data penunjang.

\section{Analisis Data}

1. Analisis deskriptif

Analisis ini digunakan untuk membandingkan hasil analisis pendapatan usahatani padi dalam program GP-PTT padi dengan hasil analisis pendapatan usahatani padi non program GP- 
PTT padi. Selain itu juga digunakan untuk membandingkan hasil $\mathrm{R} / \mathrm{C}$ ratio dalam program GP-PTT padi dengan hasil $\mathrm{R} / \mathrm{C}$ ratio non program GP-PTT padi.

Dalam penelitian ini pendapatan usahatani adalah selisih antara penerimaan dan semua biaya yang riil dikeluarkan dalam usahatani, dinyatakan dengan rumus :

$$
\begin{aligned}
& \mathrm{Pd}=\mathrm{TR}-\mathrm{TC} \\
& \text { dimana: } \\
& \mathrm{Pd}=\text { pendapatan usahatani } \\
& \mathrm{TR}=\text { total penerimaan } \\
& \mathrm{TC}=\text { total biaya yang riil } \\
&
\end{aligned}
$$

$\mathrm{R} / \mathrm{C}$ adalah penerimaan dibagi biaya dimana $\mathrm{R}$ adalah penerimaan (produksi $\mathrm{x}$ harga per $\mathrm{kg}$ ) dan $\mathrm{C}$ adalah total biaya yang riil dikeluarkan. Secara matematik, hal ini dapat dituliskan sebagai berikut:

$$
\begin{aligned}
& \mathrm{a}=\mathrm{R} / \mathrm{C} \\
& \mathrm{R}=\mathrm{Py} . \mathrm{Y} \\
& \mathrm{C}=\mathrm{TC}
\end{aligned}
$$

dimana:

$$
\begin{aligned}
\mathrm{R} & =\text { penerimaan } \\
\mathrm{C} & =\begin{array}{l}
\text { total biaya riil yang } \\
\text { dikeluarkan }
\end{array} \\
\mathrm{Py} & =\text { harga } \text { output } \\
\mathrm{Y} & =\text { output }
\end{aligned}
$$

$R / C$ Ratio $=1$ artinya tidak untung dan tidak rugi.

\section{Analisis deskriptif-kualitatif}

Analisis deskriptif-kualitatif digunakan untuk menggambarkan persepsi petani terhadap program GP-PTT padi dan dapat menggambarkan kendala-kendala yang dihadapi, sehingga dapat menggambarkan situasi dan kondisi fenomena penelitian.

\section{Analisis statistik}

Analisis statistik yang digukan adalah independent sampel t tes (uji t untuk dua sampel bebas). Uji $t$ dua sampel independent pada prinsipnya akan membandingkan rata-rata dari dua grup yang tidak saling berhubungan satu dengan yang lain, dengan tujuan apakah kedua grup tersebut mempunyai rata-rata yang sama atau tidak. Dalam penelitian ini uji $t$ dua sampel independent dilakukan dengan program SPSS 16, tujuannya adalah untuk mengetahui perbedaan pendapatan usahatani padi dalam program GP-PTT padi dengan usahatani padi non program GP-PTT padi.

\section{HASIL DAN PEMBAHASAN}

\section{Analisis perbandingan struktur biaya usahatani padi program GP-PTT padi dan non program GP-PTT padi}

Biaya yang dikeluarkan petani padi program GPPTT padi dan non program GP-PTT padi di Kecamatan Bebandem seluruhnya termasuk biaya tidak tetap, terdiri dari biaya benih, pupuk, pestisida, tenaga kerja luar keluarga dan iuran irigasi. Satu musim tanaman padi per ha program GP-PTT padi, biaya yang dikeluarkan lebih besar dibandingkan usahatani padi non program GP-PTT padi. Biaya dalam program GP-PTT padi sebesar Rp 7.899.335,97 sedangkan biaya yang dikeluarkan usahatani padi non program GP-PTT padi sebesar Rp 6.309.754,78. Biaya yang dikeluarkan dalam usahatani program GP-PTT padi lebih besar dibandingkan biaya yang dikeluarkan usahatani non program GP-PTT padi disebakan oleh dalam program GP-PTT padi menggunakan pupuk organik sedangkan non program GP-PTT padi tidak menggunakan pupuk organik. Selain itu biaya tenaga kerja dalam program GP-PTT padi juga lebih tinggi dibandingkan biaya tenaga kerja usahatani padi non program GP-PTT padi.

Komponen biaya terbesar yang dikeluarkan dalam usahatani padi program GP-PTT maupun non program GP-PTT padi adalah biaya tenaga kerja di luar keluarga dengan persentase $71,03 \%$ berbanding $80,44 \%$ dari total biaya usahatani. Terjadi perbedaan besarnya biaya tenaga kerja luar keluarga dalam usahatani padi program GP-PTT padi maupun non program GP-PTT padi terunama dalam hal penanaman. Dalam usahatani padi program GP-PTT padi rata-rata biaya penanaman dalam satu musim per ha sebesar Rp 1.417.549,67 sedangkan non program GP-PTT padi rata-rata biaya penanaman dalam satu musim per ha sebesar Rp 1.057.570,42. Perbedaan biaya tanam tersebut disebabkan karena dalam program GP-PTT padi diwajibkan untuk menanam padi dengan sistem tanam jajar legowo $2: 1$. Biaya tanam padi dengan sistem tanam jajar legowo $2: 1$ lebih tinggi dibandingkan sistem tanam tegel yang biasa dilakukan petani setempat karena buruh tani membutuhkan waktu lebih lama untuk menanam padi dengan sistem tanam jajar legowo $2: 1$.

Sebagian besar biaya riil yang dikeluarkan petani program GP-PTT padi tahun 2015 di Kecamatan Bebandem, Kabupaten Karangasem di bantu oleh pemerintah. Biaya yang dibantu adalah biaya benih Rp 250.000,00/ha, seluruh biaya pupuk dan pestisida, dan bantuan biaya tenaga kerja penanaman sebesar Rp 500.000,00/ha. Selain bantuan biaya tersebut, kelompok tani juga dibantu untuk biaya pertemuan dan biaya untuk membeli alat tanam. 
Analisis perbandingan pendapatan usahatani padi program GP-PTT padi dan non program GP-PTT padi

Rata-rata produksi program GP-PTT padi sawah dalam penelitian ini per musim sebesar $7.360 \mathrm{~kg} / \mathrm{ha}$ GKP, sedangkan rata-rata produksi non program GP-PTT padi per musim sebesar $6.802 \mathrm{~kg} / \mathrm{ha}$ GKP. Rata-rata harga jual gabah kering panen di Kecamatan Bebandem adalah Rp 3.000,00. Ratarata penerimaan usahatani dalam program GP-PTT padi dalam satu musim sebesar $\quad \mathrm{Rp}$ 22.080.298,01/ha, sedangkan rata-rata produksi non program GP-PTT padi per musim sebesar Rp 20.405.281,69/ha. Analisis perbandingan pendapatan usahatani padi program GP-PTT padi dan non program GP-PTT padi per ha per musim tanam disajikan pada Tabel 1.

Tabel 1. Perbandingan Pendapatan Usahatani Padi Program GP-PTT Padi dan Non Program GP-PTT Padi per ha di Kecamatan Bebandem

\begin{tabular}{rlrc}
\hline No. & Uraian & $\begin{array}{c}\text { Program GP- } \\
\text { PTT } \\
(\mathrm{Rp} / \mathrm{ha})\end{array}$ & $\begin{array}{c}\text { Non Program } \\
\text { GP-PTT } \\
(\mathrm{Rp} / \mathrm{ha})\end{array}$ \\
\hline 1 & Penerimaan & $22.080 .298,01$ & $20.405 .281,69$ \\
2 & Biaya & $7.899 .335,97$ & $6.309 .754,78$ \\
3 & Pendapatan & $14.180 .962,04$ & $14.095 .526,91$ \\
\hline
\end{tabular}

Dari Tabel 1 diketahui bahwa rata-rata pendapatan usahatani padi program GP-PTT padi per musim per ha lebih besar dibandingkan pendapatan non program GP-PTT padi yaitu sebesar Rp 14.180.962,04 berbanding $\mathrm{Rp}$ 14.095.526,91. Walaupun penerimaan usahatani dalam program GP-PTT padi lebih besar dibandingkan penerimaan usahahani non program GP-PTT padi akan tetapi selisih pendapatan usahatani dalam program GP-PTT padi dan usahatani non program GP-PTT padi hanya Rp $85.435,13$. Hal ini disebabkan karena biaya total yang dikeluarkan dalam usahatani program GP-PTT padi lebih besar dibandingkan biaya total yang dikeluarkan usahatani non program GP-PTT padi.

\section{Analisis perbandingan $R / C$ ratio usahatani padi program GP-PTT padi dan non program GP- PTT padi}

Analisis perbandingan $R / C$ ratio usahatani padi program GP-PTT padi dan non program GP-PTT padi per ha disajikan pada Tabel 2.
Tabel 2. Perbandingan $R / C$ ratio Usahatani Padi Program GP-PTT Padi dan non Program GP-PTT Padi per Ha di Kecamatan Bebandem

\begin{tabular}{rlrr}
\hline No. & Uraian & \multicolumn{1}{c}{$\begin{array}{c}\text { Program GP- } \\
\text { PTT Padi } \\
\text { (Rp/ha) }\end{array}$} & $\begin{array}{r}\text { Non Program } \\
\text { GP-PTT Padi } \\
\text { (Rp/ha) }\end{array}$ \\
\hline 1 & Penerimaan & $22.080 .298,01$ & $20.405 .281,69$ \\
2 & Biaya & $7.899 .335,97$ & $6.309 .754,78$ \\
5 & R/C ratio & 2,80 & 3,23 \\
\hline
\end{tabular}

Berdasarkan Tabel 2, diketahui bahwa hasil analisi $R / C$ ratio pada usahatani padi program GP-PTT padi dan non program GP-PTT padi menguntungkan dan layak untuk diusahakan karena nilai $R / C$ ratio lebih besar dari satu. Nilai $R / C$ ratio usahatani non program GP-PTT padi lebih besar dibandingkan pada usahatani padi program GPPTT. Nilai $R / C$ ratio usahatani padi program GPPTT padi sebesar 2,80 dan 3,23 untuk usahatani padi non program GP-PTT padi, artinya setiap satu rupiah biaya tunai yang dikeluarkan petani program GP-PTT padi menghasilkan tambahan penerimaan sebesar Rp 2,80 dan Rp 3,23 untuk petani non program GP-PTT padi.

Nilai $R / C$ ratio usahatani non program GP-PTT padi yang lebih besar dari usahatani padi program GP-PTT menunjukkan usahatani non program GPPTT padi lebih layak untuk diusahakan, akan tetapi dalam usahatani non program GP-PTT padi tidak menggunakan pupuk berimbang. Pupuk yang digunakan usahatani non program GP-PTT padi hanya pupuk kimia dan tidak menggunakan pupuk organik. Sedangkan dalam program GP-PTT padi menggunakan pupuk berimbang, dengan dosis paling besar adalah dosis pupuk organik. Penggunaan pupuk organik diharapkan dapat mengembalikan kesuburan tanah dan menjaga kelestarian lingkungan. Dalam jangka panjang manfaat pupuk organik akan dirasakan oleh petani.

\section{Analisis Perbedaan Pendapatan Usahatani Padi Program GP-PTT dan non Program GP-PTT}

Analisis ini dilakukan untuk mengetahui perbedaan pendapatan usahatani padi program GP-PTT padi dan non program GP-PTT padi, dilakukan dengan uji $t$ dua sampel bebas (independent sampel t test) menggunakan program SPSS 16. Hasil penelitian menunjukkan nilai $\mathrm{F}$ hitung $>0,05$ yaitu sebesar 9,094 yang artinya kedua varian populasi identik (equal variances assumed). Hasil F hitung mempunyai keputusan equal variances assumed maka sig $t$ hitung yang digunakan adalah equal variances assumed. Hasil analisis menunjukkan nilai sig $t$ hitung $>0,05$, yaitu sebesar 0,297 . Hal ini berarti bahwa rata-rata pendapatan usahatani dalam program GP-PTT padi dan non program GP-PTT padi tidak berbeda nyata. 
Salah satu faktor yang menyebabkan rata-rata pendapatan usahatanni dalam program GP-PTT padi dan non program GP-PTT padi tidak berbeda nyata adalah peningkatan biaya dalam usahatani program GP-PTT padi tidak memberikan peningkatan produksi yang tinggi. Hal ini karena dalam program GP-PTT padi menggunakan pupuk organik yang manfaatnya tidak langsung bisa dirasakan oleh petani.

\section{Persepsi Petani Terhadap Program GP-PTT Padi}

Hasil penelitian menjunjukan ada satu indikator yang menunjukkan petani sangat setuju dan ada satu indikator yang menunjukkan petani sangat tidak setuju. Indikator yang menunjukkan petani sangat setuju adalah indikator petani membutuhkan program GP-PTT padi dengan skor 5,00. Indikator yang menunjukkan petani sangat tidak setuju adalah indikator bantuan biaya tanam jarwo sesuai dengan kebutuhan petani dengan skor 1,00. Hal ini menunjukkan semua responden menyatakan sangat tidak setuju biaya tanam jarwo sesuai dengan kebutuhan petani, karena dalam program GP-PTT padi hanya dibantu untuk biaya tanam jarwo sebesar $\mathrm{Rp}$ 500.00,00/ha sedangkan petani harus mengeluarkan biaya tanam jarwo sebesar Rp 1.300.000,00 sampai dengan $1.500 .000,00$ per ha.

Secara umum persepsi petani terhadap program GP-PTT padi adalah ragu-ragu dengan skor 3,24. Hal ini menunjukkan petani tidak yakin terhadap program GP-PTT padi, salah satu penyebabnya adalah dalam program GP-PTT padi ada beberapa teknologi anjuran yang dapat menambah biaya tetapi bantuan dana yang diberikan terbatas. Petani menginginkan bantuan pemerintah diberikan secara penuh sesuai dengan kebutuhan untuk menerapkan teknologi anjuaran.

\section{Kendala-kendala yang dihadapi dalam pelaksanaan program GP-PTT padi di tingkat lapang}

Hasil penelitian menunjukkan bahwa petani menghadapi beberapa kendala dalam pelaksanaan program GP-PTT padi di tingkat lapang diantaranya adalah kendala teknis, ekonomis dan budaya. Apabila dilihat dari segi teknis kendala yang dihadapi adalah sebagai berikut.

1. Betuk atau petak sawah tidak lurus, sempit, berbatu dan terasering. Dalam program GPPTT padi mewajibkan sistem tanam jajar legowo yang membutuhkan petakan sawah lurus, cukup luas dan datar. Dalam penerapan sistem tanam jajar legowo dengan cara manual (tanpa menggunakan mesin tanam) petani atau buruh tani harus mencaplak terlebih dahulu petakan sawah sebelum ditanam. Mencaplak adalah menggaris petakan sawah dengan alat caplak sebelum ditanam, tujuannya adalah agar mempermudah saat menanam dan jarak antar tanaman sesuai. Petakan sawah yang sempit, berbatu dan terasering akan mempersulit melakukan pencaplakan dan mengurangi populasi tanaman. Petak sawah yang tidak lurus atau berliku dan terasering menyebabkan sistem tanam jajar legowo tidak begitu efektif karena kurang penuhnya sinar matahari. Begitu juga apabila menggunakan mesin tanam, petakan sawah yang tidak lurus, sempit, berbatu dan berbentuk terasering akan mempersulit dalam menggunakan mesin tanam. Sebab mesin tanam jarwo ukurannya cukup besar dan berat.

2. Petani tidak memiliki mesin tanam jajar legowo ukuran kecil dan alat tanam jajar legowo masih terbatas dimiliki oleh kelompok tani. Mesin tanam jarwo yang dimiliki kelompoktani ukurannya cukup besar dan berat, ukurannya bahakan lebih besar dari traktor sehingga petani cukup susah dalam pengoprasiannya. Alat tanam jajar legowo masih terbatas, sehingga petani saat melakukan penanaman harus menunggu giliran untuk dapat menggunakan alat tanam tersebut.

3. Buruh tani kurang terlatih dalam melakukan sistem tanam jajar legowo. Sehingga jarak tanam atau pola jajar legowo kurang tepat. Penyuluh Pertanian umumnya memberikan pelatihan atau penyuluhan tentang sistem tanam jajar legowo kepada petani, sedangkan yang melakukan penanaman adalah buruh tani.

4. Rata-rata luas garapan petani cukup sempit yaitu $0,33 \mathrm{ha}$, hal ini menyebabkan petani tidak begitu merasakan peningkatan produksi ataupun penurunan produksi yang mereka alami dalam melakuakn usahatani.

5. Petani dalam melakukan usahatani tidak melakukan pencatatan, hal ini menyebabkan petani tidak mengetahui secara pasti berapa peninngkatan atau penurunan pendapatan setelah mengikuti program GP-PTT padi.

Apabila dilihat dari segi ekonomis kendala yang dihadapi adalah sebagai berikut.

1. Dalam program GP-PTT padi biaya tenaga kerja penanaman meningkat $50 \%$. Jika melakukan sistem tanam tegel yang umumnya dilakukan, petani membutuhkan biaya tanam sebesar Rp 1000.000,00/ha sedangkan untuk sistem tanam jajar legowo 2 : 1 yang merupakan teknologi anjuran dalam program GP-PTT padi petani membutukan biaya sampai Rp 1.500.000,00/ha.

2. Penggunaan pupuk berimang dalam program GP-PTT padi meningkatkan biaya saprodi dan biaya tenaga kerja, akan tetapi tidak dapat meningkatan produksi secara signifikan. Penggunaan pupuk organik bertujuan untuk mengembalikan kesuburan tanah yang manfaatnya tidak langsung dirasakan saat digunakan. 
Apabila dilihat dari segi budaya kendala yang dihadapi adalah merubah budaya sistem tanam tegel yang sudah terbiasa dan turun temurun dilakukan petani menjadi sistem tanam jajar legowo 2 : 1. Petani meragukan teknologi sistem tanam jajar legowo karena tidak terbiasa melakukan. Selain itu sistem tanam jajar legowo ada ruang kosong $40 \mathrm{~cm}$ di antara baris rumpun tanaman yang dianggap tidak memanfaatkan lahan oleh petani. Petani terbiasa dengan sistem tanam tegel yang cukup rapat dengan jarak antara rumpun tanaman tidak lebih dari $20 \mathrm{~cm}$.

\section{SIMPULAN DAN SARAN}

\section{Simpulan}

Berdasarkan hasil penelitian dapat ditarik simpulan sebagai berikut.

1. Rata-rata pendapatan usahatani padi program GP-PTT per musim per ha sebesar Rp 14.180.962,04. Usahatani padi dalam program GP-PTT dan non program GP-PTT menguntungkan dan layak untuk diusahakan karena nilai $R / C$ ratio lebih besar dari satu, yaitu masing-masing sebesar 2,80 dan 3,23. Hasil uji t menunjukkan nilai sig thitung > 0,05 yaitu sebesar 0,297 hal ini berarti bahwa tidak terdapat perbedaan yang nyata antara rata-rata pendapatan usahatani dalam program GP-PTT dan non program GP-PTT.

2. Secara umum persepsi petani terhadap program GP-PTT adalah ragu-ragu dengan skor 3,24. Hal ini menunjukkan petani tidak yakin terhadap program GP-PTT karena dalam program GP-PTT ada beberapa teknologi anjuran yang harus diikuti sementara bantuan dana yang diberikan terbatas.

3. Kendala teknis yang dihadapi di lapangan adalah petani tidak memiliki mesin tanam jajar legowo dan alat tanam jajar legowo masih terbatas. Kendala ekonomis yang dihadapi adalah menerapkan teknologi anjuran meningkatkan biaya tenaga kerja. Kendala budaya yang dihadapi adalah merubah budaya tanam tegel yang sudah terbiasa dan turun temurun dilakukan petani menjadi pola tanam jajar legowo $2: 1$.

Saran

Saran dari penelitian ini adalah:

1. Pemerintah diharapkan memberi bantuan program GP-PTT padi kepada petani secara berkelanjutan sehingga petani mau dan mampu menerapkan teknologi anjuran.

2. Batuan alat atau mesin pertaniann yang diberikan ke kelompok tani agar disesuaikan dengan kebutuhan di tingkat lapang.

3. Petani diharapkan mengikuti teknologi anjuran dalam program GP-PTT karena dapat meningkatkan produksi.
4. Penyuluh pertanian diharapkan memberi penyuluhan tentang pentingnya penggunaan pupuk berimbang.

\section{DAFTAR PUSTAKA}

Adiwilaga, A. 1992. Ilmu Usaha Tani. Cetakan Ketiga. Bandung: Alumni.

Gunaantarini, N. N. 2010. Analisis Pendapatan Usahatani Padi Sawah di Desa Peguyangan Kangin Kecamatan Denpasar Utara. Tesis Program Pascasarjana Universitas Udayana. Denpasar.

Hadisapoetra, S. 1979. Biaya dan Pendapatan dalam Usahatani. Yogyakarta: Departemen Ekonomi Pertanian Universitas Gajah Mada.

Hermanto, F. 1988. Ilmu Usahatani. Jakarta: Penebar Swadaya.

Nasir, M. 1999. Metode Penelitian. Jakarta: Ghalia Indonesia.

Soekartawi, 2006. Analisis Usahatani. Jakarta: Universitas Indonesia.

Sumarni, R. M. N. 2011. Optimalisasi Sistem Usahatani Terdiversivikasi untuk Memaksimalkan Pendapatan Usahatani di Kota Denpasar. Tesis Program Pascasarjana Universitas Udayana. Denpasar.

Umar Husein, 2003. Riset Pemasaran dan Perilaku Konsumen. PT Gramedia, Pustaka Utama, Jakarta.

Sujarweni, W.V. 2015. SPSS untuk Penelitian. Yogyakarta: Pustaka Baru Press.

Supartama, M. 2013. Analisis Pendapatan dan Kelayakan Usahatani Padi Sawah di Subak Baturiti Desa Balinggi Kecamatan Balinggi Kabupaten Parigi Moutong (e-J. Agrotekbis.). Vol. 2: p.166-172. 
